\title{
Focus in Honor of Dr. Neil Kelleher, Recipient of the 2009 Biemann Medal
}

$\mathrm{T}$ This special focus issue of the Journal of the American Society for Mass Spectrometry celebrates the accomplishments of the 2009 Biemann Medalist, Professor Neil Kelleher. The focus contains a total of nine papers devoted to top-down mass spectrometry of proteins and oligonucleotides. The development of topdown mass spectrometry and top-down proteomics is largely due to Neil Kelleher, who has vigorously promoted this technology, starting as a graduate student and continuing today. Unlike the bottom-up approach that starts with protein fragments, top-down proteomics preserves information concerning protein isoforms and the interplay between post-translational modifications by isolating and fragmenting whole proteins in the gas phase. Neil's group has applied top-down analysis to a number of important biological systems, including the protein component of human chromatin and the posttranslational dynamics of histone $\mathrm{H} 4$ through the cell cycle. His lab over the past decade at the University of Illinois in Urbana-Champaign (and at Northwestern University in mid-2010), has three main sub-groups working in the area of top down proteomics, natural products biosynthesis/discovery, and chromatin biology. The core of the group is built around expertise in technology development for complex mixture analysis using Fouriertransform mass spectrometry.

Over the past few months, I had the opportunity to discuss with Neil his background and motivation for his research:

Joe Loo: Hi Neil. Congratulations on your selection as the 2009 Biemann Medalist for your contributions towards the development of the top-down approach. I think the readers would be interested in learning about your personal and scientific background and the motivation for your research. Let's start with your formal education. You and I share the same Ph.D. mentor, Professor Fred McLafferty, at Cornell University. How did you decide to attend Cornell?

Neil Kelleher: Thanks, Joe. That's a funny story of fate, perhaps. I was on a scholarship in Konstanz, Germany, doing moderate-to-bad synthetic chemistry when I met Fred after his spectacular seminar on combining Electrospray with FTMS. The year was 1992. The next thing I knew, I was headed to Ithaca, NY!

J.L.: Didn't you know that Ithaca is cold, snowy, and gray? I realize that Fred is an energetic and engaging person, but how did he convince you to return to the U.S. and work on a mass spectrometry project?

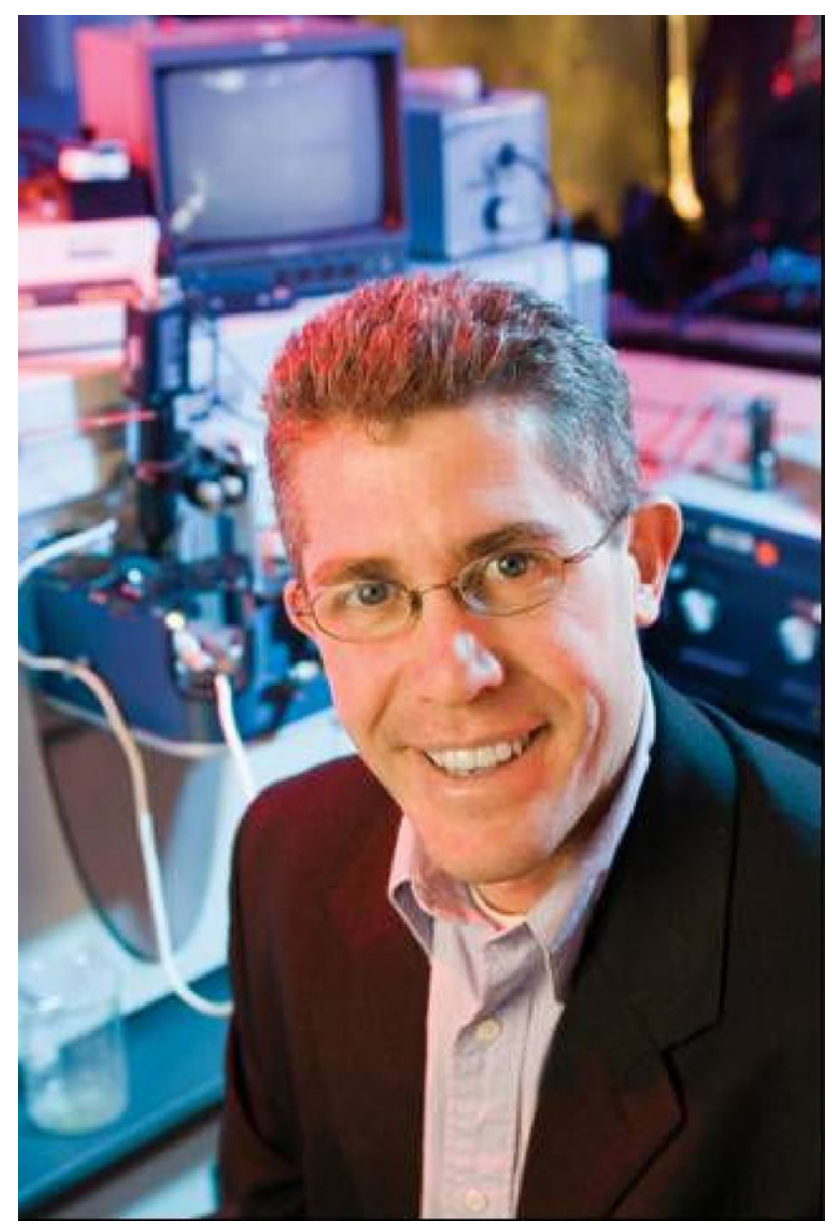

N.K.: Yeah, but I grew up near Seattle, so that didn't faze me. Fred is a persuasive force and I signed on for just a lovely summer, at first.

J.L.: What type of research did you expect to engage in when you joined Fred's group?

N.K.: Since I was synthesizing oligonucleotides in Germany, and Fred wanted to sequence DNA with mass spectrometry, it was the obvious place to begin. Life with negative ions was short-lived, and I quickly switched to proteins, in part because of a strong interest in enzyme biochemistry.

J.L.: Oh, Hi Fred (McLafferty)! I didn't see you standing there. So, what was Neil really like as a graduate student? I remembered visiting you around

(c) 2010 Published by Elsevier Inc. on behalf of American Society for Mass Spectrometry.

$1044-0305 / 10 / \$ 32.00$

doi:10.1016/j.jasms.2010.03.004 
1992. Neil was a pretty fresh student then, but my first impression of him was that he was very enthusiastic and full of energy (almost "hyper"). I also remembered him bouncing a basketball all the way down to a restaurant in Collegetown while we were walking to lunch.

Fred McLafferty: First, Neil was an "8-hour per day" man. He really did that for my research, although later Professor Tadhg Begley claimed that Neil was 8-h per day for him also. But then Professor Pete Wolczanski confessed that a qualification shortage forced him to use Neil every Friday pm for "golf research." Neil was also our greatest PR man (e.g., after my 1992 Konstanz seminar described above as "spectacular," there was dead silence-no questions-until finally this short guy in the top row asked something like "Is this the best MS research of the past decade?").

J.L.: Neil, how did the term "top-down" originate? I think the first time I read about "top-down" sequencing or the "top-down" approach was in your 1999 paper in the Journal of the American Chemical Society.

N.K.: It was in some of Fred's grant proposals and also in a letter from Fred to then-recruit Mike Senko dated November, 1990-long before I got involved. As high-throughput bottom-up took hold during the 1990s, "top-down" proteomics was a pretty clear next step as I sought gainful employment in 1999.

J.L.: Fred, is Neil's account of the origin of the "top-down" term accurate? I wasn't sure if "top-down" was used before your 1999 JACS paper. If one searches "top-down" on the Internet, the top hits describe a style of computer programming, an investment strategy, and a management and decision-making processes. If you were the first to coin "top down," then you should have trademarked it. It would have been worth a fortune.

F.M.: I haven't looked for written evidence of "topdown" use before 1990. Before electrospray, however, MS structure characterization always started with the molecular ion-how could the protein digesters not understand this? As a confession, the term "bottom-up" had connotations that expressed my opinion of their approach, which necessitated the use of "top-down" for ours.

J.L.: Thanks, Fred, for stopping by. Neil, we shouldn't neglect mentioning your other mentor at Cornell whom Fred just brought up, Professor Tadhg Begley (who recently moved to Texas A \& M University). How did your interaction with Professor Begley shape the type of research that you pursue now?

N.K.: The simple answer is "a lot." The long answer is that it sent me down the road of interdisciplinary research, which has expanded significantly in the "omic" era. More specifically, it led me into enzymology, which in turn bounced me to Chris Walsh (Harvard Medical) and ultimately explains both my hyperactive nature and the fact that about one-third of my group works in the area of natural products biosynthesis/discovery from soil and marine bacteria.

J.L.: What was your thought process in choosing Professor Walsh's lab for a post-doc? At this point in your career, had you already decided that you were headed to academia for your long-term future?

N.K.: It was more of a gut-level leap, somewhat unencumbered by the thought process. The notion was to gain more depth in enzymology to position myself better for top academic posts. I applied to Perry Frey at Wisconsin, Chris's lab, and a few other top mass spectrometry (proteomics) labs as well.

J.L.: What did you take away (not literally, of course) from each of your formal mentors (McLafferty, Begley, Walsh) that helped you in how you do scientific research currently (e.g., choosing a research problem, how you manage your group, how to write manuscripts, etc.)?

N.K.: Wow - everything!?! Fred taught me how to write, Tadhg taught me how to think in that classical, hypothesis-driven mode, and Chris pushed me to mature and think strategically. There's so much more there-just leading by example, advocacy over the years, and helping nudge me in the right direction. Soft nudges from people you revere have powerful outcomes. I now seek avenues to pay this stuff "forward."

J.L.: Since you started your academic career at Illinois, you and your group have been focused on improving the overall methodology of the top-down mass spectrometry strategy. I've been impressed that your group has expended a lot of effort in all phases of the platform, including sample preparation, instrumentation, informatics, and biological applications. In your view, which of these four aspects is the most mature and nearly "ready to go" if one considers what topdown MS will look like 5 to 10 years from now?

N.K.: My Biemann Award lecture had this basic structure to it, and I projected then that the software aspects were most refined and "ready-to-rumble." Software will always be improving, but conceptually and in a few labs, it's already there.

J.L.: Which of these areas needs the most improvement for top-down MS to be nearly as routine and widespread as the bottom-up methodology?

N.K.: That one is absolutely clear $\rightarrow$ sample preparation, especially the protein fractionation challenges above $50 \mathrm{kDa}$. Even if instruments continue on a steady course of improving by a small factor each year, they will not be limiting until the "front-end" problem for top-down has been wrestled to the ground.

J.L.: In hindsight and thinking back when you first started at Illinois, which of the four areas surprised you regarding how difficult it would be to make significant improvements?

N.K.: The separations. I'm not a chromatographer by training, but still-it has taken some remarkable talent in the lab to get this under control. It's coming, but after a decade of trying, we are just now seeing something like a platform emerging that non-aficionados can adopt.

J.L.: Is there a particular technological area that I neglected to mention that needs to be addressed before top-down will be possible on a large scale? 
N.K.: Yes and No. The "no" response describes the reality that a well-honed technology results from the contributions of many constituencies putting skin into the game-academic, corporate, and government. People are just starting to turn their attention (and resources) to the top-down horizon. So there will be dozens of labs and improvements to come over the next (half-) decade, and an engineering ethos will take hold-slowly. What could warp us ahead is the unpredictable-like a technology such as Supercharging in ESI. I know people like Evan Williams, you, and Jenny Brodbelt are working on this, so I have one message $\rightarrow$ "Hurry up"!

J.L.: Could you comment on how you envision getting top-down MS to the "masses"? What I mean by my question is that having high resolving power (and mass accuracy, of course) is a prerequisite for top down of large proteins. Currently, FT-ICR analyzers with large superconducting magnets are the primary platforms for top-down. I suppose Orbitrap performance for large proteins will improve in the future. However, both options are fairly expensive for most labs. Do you think that this situation will limit the spread of topdown MS, or do you believe that top-down will be concentrated in specialized labs that have accumulated the necessary expertise and hardware?

N.K.: There are clearly less expensive hardware options, such as benchtop FTMS (Orbitrap) systems and TOFs. ITMS often suffices for intact masses, so long as fragment ions are measured at high accuracy for reliable database searching. So I see a clear path ahead for development of both 'inexpensive' and 'expensive' flavors of top-down, but the main issue is people's mindset. Starting in expert labs, one can see evidence for propagation outward now (e.g., BioPharma), but the status of the bottom-up/top-down dichotomy a decade from now is difficult to predict.

J.L.: How do you feel about the "middle-down" approach in which larger proteins are cleaved into relatively large pieces before MS/MS analysis? Are there unique roles and/or application for the middle down strategy?

N.K.: Driven by increased use of $\mathrm{e}^{-1}$-based MS/MS, and clear successes in histone MS, this area that Catherine Fenselau called "middle molecule" MS some 20 years ago is small, but growing. My good friend and colleague Mike Senko calls this "Goldilocks" proteomics, after the famous children's story from the UK. So if intact proteins are too big right now, and little tryptic peptides are too small for maximal protein coverage, perhaps mid-sized peptides are just the ticket to get some "top down-like" advantages reaching more people and serve as a stepping-stone on the way toward more widespread and routine top-down MS.

J.L.: You've been really active in applying top down mass spectrometry to address the biosynthesis and discovery of polyketides and non-ribosomally produced peptides. I assume this originated from your work with the Walsh lab. What capabilities of the top-down approach make it especially suitable for this research area?

N.K.: The practical advantage of keeping all parts of the protein together. These enzymes all share a covalent but labile cofactor that carries all the biosynthetic intermediates. We tickle them with vibrational energy and much like the ion chemistry of phospho-peptides, this cofactor pops right off and reduces even $200 \mathrm{kDa}$ proteins down to $1+$ ions below $1000 \mathrm{~m} / \mathrm{z}$. A half-dozen or so enzymologists have used this trick at the protein level, and after hunting down the right peptide, with proteolysis as well.

J.L.: Are there applications that you're dying to get into, but you didn't feel that the current capabilities of top-down were suitable yet?

N.K.: Systems biology. Top-down has involved mostly technology development. However, levels of throughput and proteome coverage are now rising to the point where we can actively dive in, swim with the bigger fish, and make some waves.

J.L.: You've had a number of students graduate with a degree since you've been in academia. What kind of advice are you giving them as they begin their independent scientific careers?

N.K.: In short, to know more than mass spec and to seek leadership positions. Students are expected to be well-grounded in our core area of expertise, but also have great depth in at least one other area (e.g., enzymology, computer science, chromatography, or a targeted area of cell biology). Of our $\sim 20$ Ph.D.s- they have fanned out and have done quite well indeed. I get a fair amount of targeted e-mail and phone traffic seeking more talent for academic, corporate, and hybrid positions. We had a big celebration dinner at ASMS in Philadelphia. It was amazing to see how great people were doing and how fast time passes.

Joseph A. Loo Associate Editor, JASMS Department of Chemistry and Biochemistry, University of California-Los Angeles, Molecular Biology Institute, Los Angeles, California, USA 